\title{
Participación y tiempo en actividades cotidianas de hombres y mujeres vinculados al mercado laboral en México ${ }^{1}$
}

\author{
Participation and Distribution of Time in \\ Daily Activities of Men and Women Working \\ in the Labor Market in Mexico
}

\section{Participação e tempo em atividades cotidianas de homens e mulheres vinculados ao mercado de trabalho no México}

\section{María Viridiana Sosa Márquez ${ }^{2}$}

Profesora investigadora de la Universidad Autónoma del Estado de México, Ciudad de MéxicoMéxico

virisosa@yahoo.com

\section{Rosa Patricia Román Reyes ${ }^{3}$}

Profesora investigadora de la Universidad Autónoma del Estado de México, Ciudad de MéxicoMéxico

promanreyes@yahoo.com.mx

1 Artículo de investigación científica y tecnológica finalizada que no se desprende de un proyecto de investigación ni ha contado con financiamiento alguno para su desarrollo.

2 Licenciada en Administración de empresas. Maestra en Demografía. Doctora en Estudios de Población.

3 Licenciada en Trabajo Social. Maestra en Estudios de Población. Doctora en Estudios de Población. 


\title{
Resumen
}

El aumento de la participación de mujeres en el mercado laboral y la disminución de la tasa de fecundidad muestran un cambio de roles de género. Esta transformación no ha significado una readecuación de las labores entre los miembros del hogar; esto plantea un desequilibrio entre las parejas, y provoca sobrecargas y desventajas para las mujeres por la dificultad para conciliar trabajo y familia. Este estudio presenta una estimación de la participación y distribución del tiempo en actividades cotidianas por sexo, con la Encuesta Nacional sobre Uso del Tiempo 2009, para acercarnos a la organización social entre hombres y mujeres que trabajan de manera remunerada en México. Los resultados muestran los desequilibrios persistentes y las necesidades de políticas públicas en la materia.

Palabras clave: uso del tiempo; trabajo no remunerado; género; políticas públicas.

\begin{abstract}
The increased participation of women in the labor market and the declining fertility rates show a change in gender roles. This transformation has not meant a readjustment of tasks between family members. This raises an imbalance between partners, causing overload and disadvantages for women because of the difficulty of reconciling work and family. This study presents an estimate of participation and distribution of time in daily activities by sex, with the Encuesta Nacional sobre Uso del Tiempo 2009, to approach the social organization among men and women that have a paid work in Mexico. The results show persistent imbalances and the need of public policies addressing this issue.
\end{abstract}

Keywords: time use; not paid work; gender; public policies.

\section{Resumo}

O aumento da participação de mulheres no mercado de trabalho e a diminuição da taxa de fecundidade expressam uma mudança nos papeis de gênero. Esta transformação não significou um reajustamento das atividades entre os membros do lar. Assim sendo, evidencia-se um desequilíbrio entre os casais, provocando sobrecargas e desvantagens para as mulheres, devido à dificuldade de conciliação entre trabalho e família. Este estudo apresenta uma estimação da participação e distribuição do tempo em atividades cotidianas por sexo, tomando a "Encuesta Nacional sobre Uso del Tiempo 2009", com o objetivo de fazer uma aproximação à organização social de homens e mulheres que trabalham com remuneração no México. Os resultados mostram os desequilíbrios persistentes e a necessidade de políticas públicas no assunto.

Palavras-chave: uso do tempo livre; trabalho não remunerado; gênero; políticas públicas..

Este trabajo está bajo la licencia Creative Commons Attribution 3.0

¿Cómo citar este artículo? / How to quote this article?

Sosa, María y Rosa Román. «Participación y tiempo en actividades cotidianas de hombres y mujeres vinculados al mercado laboral en México». Sociedad y economía, $\mathrm{n}^{\circ} 29$ (julio - diciembre 2015): 63-89. 


\section{Introducción}

En la actualidad es urgente reconocer como un asunto de interés público, y objeto de política pública, la sobrecarga de trabajo de las mujeres que se desempeñan en ocupaciones remuneradas, sin dejar de realizar tareas domésticas y de cuidado de personas. En diversos foros académicos se ha advertido que este interés también es prioritario para promover un reparto más equitativo de estas responsabilidades entre sexos y generaciones, con el fin de contar con una efectiva conciliación entre el trabajo para el mercado, y el trabajo doméstico y de cuidado.

De acuerdo con Rogero (2006), "es en el uso que hacemos del tiempo donde se plasman las desigualdades sociales y las diferencias entre los individuos" (citado en Del Barrio 2007, 1). Sin lugar a dudas, la forma en que utilizamos el tiempo está determinada y condicionada por una serie de factores (edad, nivel socioeconómico, escolaridad, acceso a servicios y bienes, etc.), entre los cuales la condición de género es fundamental, ya que los roles asignados social, histórica y culturalmente a hombres y mujeres definen en gran medida el tipo de actividades que realizan dentro y fuera de sus hogares de pertenencia, así como el tiempo que involucran en esas actividades.

Algunos de los estudios sobre la participación laboral se han centrado en las mujeres y su problemática para poder conciliar trabajo y familia. Así, por ejemplo, García y Oliveira, al estudiar las relaciones de género, señalan que:

\section{Estudios de caso sobre la importancia del trabajo extradoméstico en la vida de las mujeres, y en particular en sus relaciones de pareja, ha permitido sostener en mu- chas ocasiones que la participación laboral no ha traído los cambios fundamentales que muchos/as han postulado en la condición de subordinación femenina (2007, $53)$.}

En este sentido es importante tener presente que a partir de la década de 1990, y con la continuidad y agudización de los problemas económicos del país, comenzó a evidenciarse que la mayor participación en los mercados de trabajo de las esposas no solo no constituyó una respuesta de los hogares con ingresos más bajos, sino que también se extendió a unidades domésticas de sectores medios con mano de obra escolarizada (García y Pacheco 2000). El incremento de la participación de las esposas en el mercado de trabajo se ha asociado con la ampliación de las oportunidades de empleo para algunas mujeres con mayor escolaridad, con el descenso de la fecundidad y especialmente con la respuesta que adoptaron muchas mujeres para enfrentar el descenso en sus niveles de vida.

$\mathrm{Al}$ revisar esta situación no deja de impactar el hecho de que a pesar del incremento durante las últimas décadas de la participación femenina en el trabajo remunerado, sigue siendo mucho menor que la participación masculina debido a una diversidad de factores, como la discriminación en las prácticas de contratación, remuneración, movilidad y ascenso; las condiciones de trabajo inflexibles; la insuficiencia de servicios tales como los de guardería, y la distribución inadecuada de las tareas familiares en el hogar, entre otros.

García $(2012,133)$ indica que si bien teóricamente la incorporación generalizada de la mujer al mercado de trabajo plantea la necesidad de redistribuir 
las actividades del hogar -pues ellas ya no son las únicas responsables de su realización como ocurre en el modelo tradicional-, en la práctica no siempre las parejas en las que ambos trabajan rompen con este modelo tradicional de familia. La Organización Internacional del Trabajo (OIT) refuerza esta aseveración al enfatizar que el trabajo productivo y el reproductivo se han organizado históricamente sobre la base de rígidos y estereotipados roles de género que lenta y sistemáticamente han ido transformándose, generando tensiones para las mujeres pero también para la vida familiar. Desde la OIT, el discurso preponderante sobre este tema es que "no es posible enfrentar la exclusión social, la desigualdad y la pobreza si no se aborda al mismo tiempo y con la misma energía la sobrecarga de trabajo de las mujeres y la falta de oportunidades ocupacionales para ellas" (OIT 2009, 11 ).

Así, es imprescindible considerar en esta discusión que la reproducción sociosimbólica de las sociedades tiene en cuenta de forma preponderante las construcciones socioculturales de lo masculino y de lo femenino, y con ello la ideología de género, es decir, la naturalización de la división social del trabajo. Desde esta perspectiva, consideramos importante analizar tanto a los hombres como a las mujeres que participan en el mercado laboral, donde se supone que en puestos y ocupaciones similares debería existir mayor igualdad de circunstancias y condiciones de trabajo; sin embargo, esto no es así; persiste una presencia de importantes inequidades en nuestro país.

Para realizar este análisis el trabajo se estructura en cinco apartados, comenzando por una revisión de los principales antecedentes de relación de los ámbitos públicos y privados de vinculación de la vida de hombres y mujeres. El segundo apartado presenta las características, potencialidades y limitaciones de la Encuesta Nacional sobre Uso del Tiempo 2009 (ENUT-09) (Inegi 2010), fuente de información utilizada en este estudio, para dar paso, en el tercer apartado, al desarrollo del abordaje metodológico cuantitativo, mediante el cual se procesaron y generaron los datos necesarios para llevar adelante el análisis propuesto. En el cuarto apartado se discuten y analizan los resultados más destacados y, finalmente, el quinto apartado expone algunas reflexiones finales.

\section{Antecedentes}

La división del trabajo en función del sexo responde a cuestiones sociales, económicas y culturales que dan cuenta de un reparto de funciones y espacios para llevarlas a cabo, históricamente diferenciadas: las mujeres en el ámbito privado y los hombres en el ámbito público (Inmujeres 2013). Esta diferenciación ha producido una tenaz desigualdad de las oportunidades que las mujeres tienen. Primero, por ser las encargadas de las funciones dentro del hogar, llevadas a cabo para sus miembros, sin reconocimiento alguno de que las actividades desempeñadas son trabajo, sin remuneración y sin un horario fijo. Segundo, porque esa desigualdad se amplía cuando al dominio de la esfera de la vida privada, en el caso de muchas mujeres se suma la actividad en el espacio público, cuando desarrollan actividades extradomésticas.

Por otra parte, la demanda de cuidados en el hogar (fundamentalmente a niños, adultos mayores y personas enfermas, cuando es el caso) recae principalmente 
en las mujeres. Esta situación, en un gran número de ocasiones, las imposibilita para acceder al mercado laboral remunerado o provoca intermitencias en su inserción. De acuerdo con una publicación del Instituto Nacional de las Mujeres (Inmujeres) de México, las mujeres realizan actividades de cuidados, independientemente de si participan en actividades económicas y además -según ellas reportan- en su mayoría, son las únicas cuidadoras de sus hogares; también muestra indicios incipientes de que a medida que la mujer trabaja de manera remunerada hay más participación en actividades de cuidado de personas por parte de todos los miembros del hogar. Aunque en general, los cuidados son satisfechos por otras mujeres y sus necesidades tienen que tomarse en cuenta en el establecimiento de políticas de conciliación laboral y familiar: licencias de paternidad; ampliar servicios de guarderías, estancias infantiles y escuelas; horarios y jornadas de trabajo adecuados; opciones laborales como el trabajo a distancia e incentivos a cuidadores (Inmujeres 2013).

Algunas consideraciones sobre la relación entre la participación laboral de las mujeres casadas y la fecundidad se muestran en un estudio que señala que la decisión de estas sobre reincorporarse al mercado laboral depende de su nivel educativo y de su situación laboral previa al inicio de la maternidad (Norman 2006).

El mercado laboral ofrece un espacio de "libertad" a las mujeres, aunque independientemente de que lleven a cabo estas labores también son ellas quienes realizan los quehaceres domésticos y no suelen ser reemplazadas en esta responsabilidad por otros miembros del hogar. En los casos en los que es así son otras mujeres -madres o hijas- quienes comparten estas tareas. Las labores que refieren menores resistencias por parte de los hombres para ser compartidas, de acuerdo con algunos estudios, son las de cuidado y atención de los hijos (Nieves 1998). Este hecho también se aprecia en un estudio previo de Sosa (2010) que utiliza igualmente la ENUT-09 donde se aprecian importantes porcentajes de participación de hombres (Sosa 2010).

Se ha encontrado en estudios sobre la distribución o el uso del tiempo de mujeres casadas o con pareja que independientemente de que se dediquen a su casa solamente o que también se encuentren insertas en el mercado laboral, todas ellas tienen una doble jornada de trabajo; pero en el caso de las mujeres que son amas de casa, estas dedican más tiempo a las tareas domésticas como las compras (diarias) o hacen comidas más elaboradas, mientras que en el caso de las mujeres que también trabajan fuera del hogar existe una mayor participación de los hombres (Bosch, Ferrer y Gili 1996).

Durán (2007) sostiene que, en España, generalmente los varones reducen su involucramiento en el cuidado de niños cuando este aumenta de uno a más hijos. Lo más frecuente es que el cónyuge se responsabilice del cuidado de los hijos (35\% en promedio) y más de una cuarta parte de los trabajadores que cuidan hijos utilizan la ayuda de otros familiares (abuelas, hermanas e hijas, principalmente).

Esta misma autora comenta que el hecho de que las mujeres se incorporen al mercado laboral no las libera de ser las principales responsables y trabajadoras de actividades no remuneradas de sus hogares. Muestra, con una encuesta sobre actividades no remuneradas, la gran disparidad de tiempo destinado a las labores domésticas existente entre hombres y mujeres, ya que en las mismas 
circunstancias de participación en el mercado laboral, el tiempo destinado a estas actividades es de 135 minutos los hombres versus 346 minutos de las mujeres. Con lo anterior demuestra que en España los patrones tradicionales de empleo del tiempo en función del género persisten aun cuando las mujeres tienen acceso al ámbito público o profesional (Durán 2003).

En fechas recientes, otros estudios para México muestran que aunque la mayoría de los hombres y mujeres en edades productivas ( 24 a 64 años) siguen un patrón de uso del tiempo que puede considerarse como tradicional ${ }^{4}$, existe un grupo que puede considerarse como "innovador"; esto es, mujeres que desempeñan roles habitualmente seguidos por hombres ${ }^{5} \mathrm{y}$ varones que siguen patrones de empleo del tiempo regularmente seguidos por mujeres ${ }^{6}$. En ambos casos se trata de personas menores de 45 años y con niveles educativos altos (Rivero y Pederzini 2014).

En lo que se refiere al cuidado de las personas se debe tomar en cuenta el ciclo de vida y el de los propios hogares, ya que esto determinará las necesidades de cuidado. Es decir, si tenemos a una mujer en edad reproductiva y productiva, su carga de cuidados será más grande a medida que tenga hijos, se incorpore en el mercado laboral, etc. En este sentido, la edad que tengan los hijos también imprimirá a las actividades de cuidado necesidades de tiempo diferenciales (i.e. se supone que una mujer de 30 años de edad con dos hijos menores de 6 años destinará al cuidado de los miembros del hogar más tiempo que una mujer con hijos adolescentes o con hijos casados y/o insertos en el mercado laboral); y el cuidado en sí mismo también puede ser distinto, ya que los niños pequeños dependen de los adultos en mayor medida que los adolescentes, quienes no por ello dejan de requerir el cuidado.

De acuerdo con los resultados de la ENUT-02 -encuesta previa a la actual levantada en el 2009-40,4\% de las personas encuestadas participan en el cuidado de niñas, niños, enfermos y miembros del hogar; $2,4 \%$ en el cuidado de enfermos y 2,0\% en el de personas con limitaciones físicas o mentales; es decir, destinan en promedio 11:12, 7:12 y 8:00 horas a la semana a estas actividades, respectivamente. De estos resultados, la participación de hombres y mujeres en estas actividades es: $30,6 \%$ y $49,3 \% ; 1,6 \%$ y $3,2 \%$ y $1,6 \%$ y $2,4 \%$, respectivamente. Y las horas promedio 7:18 y 13:24 horas, 7:54 y 6:54 horas, así como 5 y 9 horas, respectivamente. Esto indica que las mujeres participan más y destinan mayor número de horas a las actividades de cuidado de miembros del hogar (Inegi 2005, 26), resultados que van en la misma línea de lo encontrado en otros estudios que analizan esta misma encuesta (Pedrero 2005).

Estos hallazgos han sido ratificados por autores como Rojas (2010), quien plantea que aún está vigente en México la creencia compartida por hombres y mujeres de que los hijos deben ser atendidos en forma exclusiva por sus madres, así como la valoración del papel social de los hombres como proveedores de sus hogares. Rojas afirma que:

4 Mujeres dedicadas a las labores del hogar y hombres dedicados al empleo remunerado.

5 Dedican mayor número de horas al trabajo remunerado, y menos horas al cuidado de personas y labores domésticas que otras mujeres.

6 Dedican una gran cantidad de tiempo al cuidado de personas y al trabajo del hogar. 
Las tradiciones, valores y normas culturales en México asumen como femenino los trabajos reproductivos: procreación, cuidado y socialización de los hijos (...) La maternidad, en contraposición al trabajo extradoméstico, termina por construirse en el eje organizador de las vidas de las mujeres y es en muchas ocasiones solamente a través de ella que obtienen legitimidad y reconocimiento social $(2010,35)$.

De acuerdo con estos resultados de la ENUT-02, la mayor parte del tiempo de cuidado brindado a los miembros del hogar (3,2\% sobre el total de actividades) está dado por las mujeres: 4,5\% del tiempo total semanal contra 1,65\% de los hombres. De esta proporción, el grupo de edad donde se concentra la realización de esta actividad es en el de 20 a 59 años, es decir, en las edades productivas en términos de mercado (Inegi 2005, 15-16). En este sentido, las personas dentro del hogar que brindan este servicio a los demás miembros suelen ser las mujeres cónyuges, seguidas por otros parientes miembros del hogar, siendo menor el tiempo designado por los hombres y por los hijos e hijas (Inegi 2005, 19). Ahora bien, en cuanto al tiempo de cuidado por situación conyugal, las mujeres casadas destinan más horas a la semana al cuidado de miembros del hogar (6,1\% del total de horas a la semana destinado a todas las actividades); comparado con las destinadas por los hombres casados $(2,2 \%)$ se entiende la magnitud de la diferencia, que es tres veces mayor; 2,5 veces más que las mujeres solteras y dos veces más que las divorciadas, viudas y separadas (Inegi 2005, 25).

Cuando existen en el hogar niñas y niños menores de 12 años, el tiempo destinado a la actividad de cuidado se duplica (6:42 sin niños menores y 12:00 horas con niños menores) y son las mujeres quienes, en mayor medida, asumen la responsabilidad del cuidado de estos menores (7:48 los hombres y 14:24 horas las mujeres) (Inegi 2005, 58-59).

Sobre las diferencias de tiempo invertido en el cuidado de miembros del hogar en relación con si ambos cónyuges participan en el mercado laboral o no, encontramos que independientemente de su incorporación en este, las mujeres destinan poco menos del doble de tiempo que los hombres a esta actividad (12:24 versus 7:54 horas); mientras que en los casos en los que solo el hombre trabaja fuera, el tiempo de las mujeres sube a 16:18 y el de los hombres se mantiene 7:54 horas (Inegi 2005, 62). Lo anterior evidencia un reparto inequitativo de las labores de cuidado de miembros del hogar entre las parejas, independientemente de la participación en el mercado laboral, y refuerza nuestro supuesto; las familias mexicanas mantienen una organización tradicional en sus estructuras y dinámicas a pesar de la creciente incorporación de la mujer al mercado laboral. En este punto es importante reflexionar sobre la importancia de las políticas públicas de apoyo para el cuidado de menores en particular. La carencia o dificultad para acceder a servicios de cuidado de niños y niñas es un problema que pareciera ser asumido mayormente por las mujeres, en tanto son ellas las que en mayor medida asumen el rol de cuidadoras.

En este sentido es esperable que las políticas y programas públicos se orienten, como plantea Flaquer, a:

Hacer posible que las necesidades de los miembros de las unidades familiares, sean satisfechas tanto a través de las dependencias y solidaridades mutuas, que constitu- 
yen el núcleo de las relaciones familiares, como a través de la aportación de recursos externos derivada de la actuación o de la previsión de organismos públicos (2000, $16)$.

De acuerdo con la Encuesta Nacional sobre la Dinámica de las Familias, (Endifam 2005)7, la proporción de personas que declaran haber dado ayuda en la vida cotidiana es un poco mayor entre mujeres que entre hombres (alrededor de $34 \%$ en hombres y $36,7 \%$ en mujeres). Ahora bien, una proporción menor, pero mayor entre las mujeres, declara haber recibido alguna ayuda $(25,8 \%$ de hombres y $27,8 \%$ de mujeres). Se encuentra también que es la mujer quien más ayuda brinda en caso de una enfermedad grave.

Estos datos no hacen sino evidenciar la persistencia de algunos de los principios básicos sobre los que se fundamenta el modelo tradicional de familia en nuestro país, y lo hace en parejas en las que ambos participan en el mercado laboral, hecho que por definición rompe con el principio más elemental de este modelo: dejar en manos del hombre las tareas productivas. A pesar de que la masiva incorporación de la mujer al mundo laboral sacude uno de los pilares del modelo, parece que no altera otros aspectos que le son consustanciales, como es el desigual reparto de las tareas del hogar (Ajenjo y García 2011). Los datos al menos así lo indican.

En este sentido, la propuesta es que los trabajos sean compartidos; si ambos miembros de las parejas se encuentran insertos en el mercado laboral, debe haber una redistribución de las tareas dentro del hogar para que no sean las mujeres quienes tengan que buscar el tiempo para compatibilizar todo, ya que "el agobio surge de la exclusividad" en el desempeño de las labores domésticas (Nieves 1998, 99). En el hecho de que el trabajo doméstico constituya un área predominantemente femenina, influye sin lugar a dudas el reconocimiento de que resulta imposible pensar en la vida de las mujeres sin pensar en las familias de las que forman parte, ya que para las mujeres, en mayor medida que para los hombres, las decisiones individuales son inevitablemente decisiones de índole familiar, y las decisiones familiares influyen fuertemente en su trayectoria individual (Kuznesof 1992).

Respecto de estas diferencias entre hombres y mujeres en cuanto al peso de la familia, Kuznesof (1992) sostiene que mientras que para los hombres una carrera profesional o un empleo son y han sido siempre "primarias" en su identidad, y en las funciones de su vida (como seres individuales y como miembros de una familia), para las mujeres esto no es así. Las mujeres, particularmente en América Latina, se identifican en primer lugar con sus funciones como "criadoras" y "proveedoras" en el contexto familiar, siendo el tema del empleo o de la profesión una cuestión secundaria, que es realizada como un complemento de sus actividades en el hogar o en caso de problemas económicos en la familia. El empleo es raramente visto como una identificación primaria de la mujer como parte de un grupo familiar.

7 La Encuesta Nacional sobre la Dinámica de las Familias 2005 fue financiada por el Sistema Nacional para el Desarrollo Integral de la Familia y realizada por el Instituto de Investigaciones Sociales (IIS) de la Universidad Nacional Autónoma de México (UNAM). 
En este sentido, y a pesar de las transformaciones crecientes en las estructuras familiares, el reparto de las actividades domésticas sigue siendo desigual:

\begin{abstract}
La negociación del reparto de responsabilidades económicas y domésticas ha dado lugar a situaciones muy desiguales, caracterizadas por una incorporación muy extendida de las mujeres en pareja al trabajo remunerado y una incorporación muy limitada de los varones en pareja al trabajo no remunerado, en un contexto en el que el discurso social tiende a ser el de 'una familia en la que tanto el hombre como la mujer trabajan fuera de casa y se reparten las tareas del hogar y el cuidado de los hijos' (Meil 2005, 178).
\end{abstract}

El estado del arte muestra evidencias que exponen la desigualdad en el reparto de tareas entre hombres y mujeres dentro de los hogares. Esta distribución suele ser diferencial también de acuerdo con la edad de las personas, su situación conyugal, su posición en el trabajo y el nivel escolar alcanzado, entre otras. Es por esta razón que decidimos incorporar estas variables en nuestro análisis.

\title{
2. Fuente de datos
}

Para el desarrollo del análisis propuesto utilizamos los datos provenientes de la Encuesta Nacional sobre Uso del Tiempo 2009 (ENUT-09), la cual permite conocer la participación y el tiempo que hombres y mujeres de 12 años y más destinan a las actividades cotidianas a lo largo de una semana, esto es, al trabajo remunerado, al trabajo no remunerado y a las actividades personales; y sigue los lineamientos establecidos por la Organización de las Naciones Unidas (ONU 2006).

El Instituto Nacional de Estadística y Geografía (Inegi) fue el encargado de llevar a cabo el levantamiento de la ENUT-09, en conjunto con el Instituto Nacional de las Mujeres, a finales del 2009. La encuesta se realizó de manera independiente y se incluyeron preguntas específicas sobre una gran gama de actividades remuneradas, no remuneradas y de ocio que permiten articular el uso del tiempo con perspectivas económicas y/o demográficas.

El universo de análisis son los hogares de viviendas particulares con integrantes de 12 años y más. Se preguntó a las personas por el tiempo destinado a actividades cotidianas durante la semana anterior a la fecha de la entrevista, en dos ciclos semanales (lunes a viernes, y sábado y domingo). La entrevista se realizó a través de un cuestionario electrónico, de manera directa. Sus datos permiten dar cuenta de información nacional, por localidad y para cuatro regiones: Centro, Centro-Occidente, Norte y Sur-Sureste. En nuestro caso particular el nivel de análisis será el nacional.

El diseño de la muestra fue probabilístico, bietápico, estratificado y por conglomerados, siendo la última unidad de selección la vivienda y la unidad de observación el hogar, quedando finalmente una muestra estadística de 17.000 viviendas levantadas en el ámbito nacional (Inegi 2012).

La encuesta contiene información sobre características de la vivienda, características sociodemográficas de las personas, y sobre actividades de trabajo remunerado (condición de actividad, características del trabajo y trabajo de autoconsumo), actividades domésticas (de quehaceres del hogar, cuidado de personas 
y comunitarias), así como actividades personales (de aprendizaje y estudio, convivencia y recreativas, uso de medios de comunicación y cuidados personales). Todas estas temáticas son recabadas por medio de preguntas cerradas sobre 82 actividades cotidianas, las cuales pretenden abarcar todas las actividades que una persona puede desarrollar a lo largo de una semana.

En específico, este instrumento de captación se basa en actividades predeterminadas, no en un diario de tiempo abierto con las 24 horas del día como guía. Es por ello que las personas pueden declarar sobre las actividades que se les preguntan: cuáles realizaron durante la semana pasada y el tiempo que les destinaron, sin importar si estas se llevaron a cabo de manera simultánea o no. Debido a lo anterior, la suma de los tiempos no necesariamente será igual a las 168 horas semanales, lo cual podríamos esperar de una encuesta que se levanta con un diario donde sí se controla el tiempo. A pesar de estas dificultades metodológicas, consideramos relevante utilizar estos datos haciendo las precisiones necesarias, de la misma manera que se señala en una publicación de la CEPAL sobre potencialidades y restricciones de las encuestas sobre uso del tiempo (Milosavljevic y Tacla 2007).

A pesar de que en la ENUT-09 no se preguntó si las actividades se hacían o no de manera conjunta con otras, sí se incluyeron algunas preguntas sobre qué actividades solían hacerse "al mismo tiempo"; información que permitiría por lo demás tener un acercamiento al tema de la simultaneidad de las actividades, que no es materia de análisis en el presente estudio.

\section{Metodología}

Los datos de esta encuesta, como se mencionó anteriormente, permiten estimar el porcentaje de participación de las personas a las diferentes actividades contenidas en esta, así como el tiempo destinado al desarrollo de las mismas (horas promedio semanales dedicadas a la actividad calculadas para aquellas personas que declararon haberla realizado) para la población de 12 años y más, en un primer momento, y para los jefes y cónyuges insertos en el mercado laboral, en el siguiente. La información obtenida se estructura de acuerdo con la clasificación de actividades de uso del tiempo para América Latina y el Caribe (Cautal) ${ }^{8}$.

La información de esta encuesta permite conocer los roles de hombres y mujeres en nuestro país en la primera década del siglo XXI. Para la obtención del porcentaje de participación se consideró, primero, si la persona realizó cada una de las 82 actividades, donde participar fue igual a 1 y no participar igual a 0 . La forma de presentar estos resultados es en porcentaje de participación de las personas. Posteriormente, de quienes declararon haber realizado la actividad se sumó el tiempo dedicado a esta, es decir, las horas y minutos dedicados de lunes a viernes, así como las de sábado y domingo, para obtener un tiempo total

8 La Cautal es una herramienta para la planeación, el procesamiento, la presentación y el análisis de las encuestas de uso del tiempo. Clasifica todas las actividades que la población puede realizar durante 24 horas de un día o en una semana, las cuales pueden agregarse en tres grandes rubros: actividades de trabajo remunerado, actividades de trabajo no remunerado, y actividades personales; o desagregarse, de acuerdo con los requerimientos de información (Gómez 2010). 
semanal dedicado por cada una de las personas a cada actividad desempeñada. Lo anterior con el fin de contar con un indicador de tiempo promedio a la semana (en horas y decimales) para cada una de las 82 actividades.

La estimación de la participación de hombres y mujeres en las diversas actividades se realizó considerando si habían desempeñado o no la actividad específica, y para la conformación de las categorías agregadas se tomaron en cuenta que al menos se hubiera realizado una de las actividades que integran la división. Para contabilizar el tiempo semanal destinado a las distintas actividades se sumaron las horas y minutos declarados - de lunes a viernes y de fin de semanacomo destinados a cada una de las actividades desarrolladas que conforman la categoría.

Como eje ordenador de la información, utilizamos la clasificación de actividades de uso del tiempo para América Latina y el Caribe (Cautal), que es un componente de los lineamientos para armonizar las encuestas sobre uso del tiempo. Esta clasificación tiene como referentes al Sistema de Cuentas Nacionales (SCN) 2008, la clasificación internacional de actividades para estadísticas sobre uso del tiempo (International Classification of Activities for Time Use Statistics -Icatus-) y las resoluciones de la Organización Internacional del Trabajo (OIT) referentes al tema. En la Icatus se busca comprender el trabajo de manera integral, es decir, considerando tanto las actividades remuneradas como las no remuneradas, por lo que su marco conceptual descansa sobre un concepto extendido de producción que tiene como finalidad servir de base para la estimación de la Cuenta Satélite de Hogares. El SCN permite varios niveles de agregación según el objetivo del estudio -se puede presentar por grandes divisiones, divisiones, grupos, clases y subclases (Gómez 2010, 20)-. Para el presente análisis, la información se presenta en los niveles de grandes divisiones y división: para la población de 12 años y más, a un dígito (tabla l) y para los jefes y cónyuges a dos dígitos (anexo l).

En el diseño de la encuesta se consideró captar algunas actividades consideradas como simultáneas, i.e. esperar el gas que pertenece a las actividades domésticas no remuneradas o estar pendiente de alguien que forma parte de las preguntas de cuidado a miembros del hogar no remunerado, las cuales se excluyeron de la suma del tiempo semanal, ya que deben tener un tratamiento aparte.

Tal y como se mencionó antes, este instrumento de captación se basa en actividades predeterminadas, donde las personas declaran sobre las 82 actividades que se les preguntan: cuáles realizaron durante la semana pasada y el tiempo que les destinaron. Reiterando que la suma de los tiempos no necesariamente será igual a las 168 horas semanales. Con el fin de que este hecho permita hacer una comparación entre sexos, buscamos estandarizar los datos, transformando el tiempo declarado en porcentaje de tiempo destinado a cada una de las actividades, siendo el $100 \%$ el total de tiempo semanal declarado por hombres o por mujeres.

A partir del procesamiento de la base de datos de la ENUT-09 se obtuvieron los indicadores anteriormente explicados sobre el porcentaje de participación en la actividad y el tiempo promedio semanal asignado a la misma, esto para el total de la población de 12 años y más, y para los jefes de hogar y cónyuges que se encuentran insertos en el mercado laboral, ambos desagregados por sexo. 
Esta estimación de la participación y el tiempo de hombres y mujeres en las actividades remuneradas, no remuneradas y personales, pretende dar cuenta de la distribución del trabajo y de las funciones asignadas entre ellos. En específico se busca hacer una contabilización del reparto de las diferentes tareas cotidianas declaradas en la ENUT-09 por los hombres y las mujeres que se encuentran en el mercado laboral, con el fin de detectar sus diferencias en participación y en tiempo.

\section{Resultados}

El porcentaje de participación y el tiempo promedio semanal de la población de 12 años y más en actividades cotidianas semanales desagregado por sexo se presenta en la tabla l. En cuanto a las personas que realizan actividades económicas remuneradas, los hombres, como era de esperarse, tienen mayor participación; aunque cabe hacer notar la mayor proporción de participación de las mujeres en actividades de autoconsumo de los hogares.

Tabla 1. Participación y tiempo de la población de 12 años y más en actividades cotidianas según sexo. México, 2009

\begin{tabular}{|c|c|c|c|c|c|c|}
\hline & \multicolumn{2}{|c|}{ Total } & \multicolumn{2}{|c|}{ Hombres } & \multicolumn{2}{|c|}{ Mujeres } \\
\hline & Participación & Tiempo & Participación & Tiempo & Participación & Tiempo \\
\hline & $\%$ & Horas & $\%$ & Horas & $\%$ & Horas \\
\hline Población de 12 años y más & \multicolumn{2}{|c|}{83.664 .409} & \multicolumn{2}{|c|}{39.622 .403} & \multicolumn{2}{|c|}{44.042 .006} \\
\hline \begin{tabular}{|l|} 
A. Actividades de trabajo \\
remunerado
\end{tabular} & 65,2 & 43,7 & $\mathbf{7 7 , 5}$ & 51,43 & 54,1 & 33,73 \\
\hline 1. Trabajo remunerado & 63,6 & 39,89 & 75,0 & 47,14 & 53,4 & 30,72 \\
\hline $\begin{array}{l}\text { 2. Actividades relacionadas con el } \\
\text { trabajo remunerado }\end{array}$ & 51,8 & 6,02 & 70,1 & 6,45 & 35,3 & 5,24 \\
\hline \begin{tabular}{|l|} 
B. Actividades de trabajo no \\
remunerado
\end{tabular} & 96,8 & 32,2 & 95,1 & 15,49 & 98,4 & 46,72 \\
\hline $\begin{array}{l}\text { 3. Actividades domésticas NR para } \\
\text { el propio hogar }\end{array}$ & 93,6 & 23,88 & 89,9 & 9,51 & 97,0 & 35,86 \\
\hline $\begin{array}{l}\text { 4. Cuidado a miembros del hogar } \\
\text { no remunerados }\end{array}$ & 75,2 & 10,68 & 70,4 & 8,17 & 79,5 & 12,69 \\
\hline $\begin{array}{c}\text { 5. Actividades NR p/otros hogares, la } \\
\text { comunidad y trabajo voluntario }\end{array}$ & 11,2 & 7,1 & 8,0 & 5,36 & 14,0 & 8 \\
\hline C. Actividades personales & 100,0 & 95,71 & 100,0 & 96,09 & 100,0 & 95,36 \\
\hline 6. Aprendizaje y estudio & 1,4 & 38,97 & 19,6 & 38,82 & 19,2 & 39,11 \\
\hline $\begin{array}{l}\text { 7. Convivencia y actividades } \\
\text { recreativas }\end{array}$ & 77,5 & 9,95 & 78,4 & 10,78 & 76,8 & 9,19 \\
\hline $\begin{array}{l}\text { 8. Utilización de medios de } \\
\text { comunicación }\end{array}$ & 85,7 & 12,95 & 88,3 & 13,49 & 83,3 & 12,44 \\
\hline 9. Cuidados personales & 100,0 & 69,34 & 100,0 & 68,12 & 100,0 & 70,44 \\
\hline
\end{tabular}

Fuente: elaboración propia con datos de la ENUT-09 (Inegi 2010).

Un primer dato a destacar es la importancia de las mujeres en las actividades para el propio hogar. Es tal la magnitud de este fenómeno que se ha intentado incluso integrarlo, sin lograrlo aún, en los sistemas de cuentas nacionales. Este esfuerzo tropieza con la insistente invisibilidad del trabajo de autoconsumo de las mujeres. 
Consideramos importante presentar información desagregada para el rubro de cuidado de personas porque sus proporciones ${ }^{9}$ no son de despreciar, sobre todo en lo que se refiere al cuidado de niños menores de 15 años (33,3\%) y personas de 15 a 59 años (66,7\%). Otras actividades que también llaman la atención por los porcentajes que presentan son las de ver la televisión (73\%) y convivencia social $(69,8 \%)$ que reportan un importante número de personas.

Los resultados anteriores muestran que la participación de los hombres solo suele ser mayor en pocas actividades: el trabajo remunerado, el traslado al trabajo (relacionado con la actividad anterior), buscar trabajo, mantenimiento del hogar y algunas actividades de tipo personal. Sin embargo, en la mayoría de las actividades la participación de las mujeres supera a la de los hombres, principalmente en las que se refieren a las labores domésticas no remuneradas como la preparación de comida, limpieza de la vivienda y limpieza de ropa y calzado. Si comparamos los porcentajes de participación en estas actividades mencionadas encontramos diferencias, aunque no de gran calado. Sin embargo, al comparar el tiempo destinado estas se agudizan, mostrando inequidades muy grandes, sobre todo en las actividades de trabajo no remunerado.

La desigual distribución de las tareas domésticas en los hogares mexicanos muestra la permanencia de roles de género, en particular cuando se observa que tanto la tasa de participación como el promedio de horas dedicadas a cada actividad en el hogar tiene diferencias considerables entre hombres y mujeres.

Lo anterior pone en evidencia los roles de género asignados en nuestra sociedad, donde sigue presente la separación de las esferas pública y privada en la vida de hombres y mujeres. Por otro lado, también deja ver los desequilibrios existentes en el desempeño de las actividades no tanto en cuanto a participación como en tiempo, donde resalta el poco tiempo dedicado por parte de los hombres a las actividades domésticas y de cuidado de personas.

Los datos evidencian que la participación y el tiempo de los hombres en el trabajo doméstico se construyen y desarrollan como un proceso distinto y diferenciado del trabajo doméstico que llevan a cabo las mujeres. Señala Cacique (2008) que los integrantes de la familia de cada sexo intervienen en estas labores condicionados principalmente por prescripciones y establecimientos sociales asignados a su identidad de género, y en menor medida como resultado de estrategias o respuestas para asumir las diversas condiciones individuales y de pareja.

El hecho de que son las mujeres quienes desempeñan estas actividades y quienes más tiempo les destinan, y que además no son pagadas ni reconocidas como trabajo, marca una desventaja para ellas. Si consideramos que una gran parte de las mujeres se dedica exclusivamente a labores domésticas y de cuidado no remuneradas durante toda su vida, y que cuando llegan a edades avanzadas pueden ya no tener pareja -por ruptura de unión o viudez-, así como tampoco cuentan con seguridad social, se encontrarán sin opciones para poder salir adelante. Por si esto fuera poco, también se les asigna una sobrecarga de trabajo que por el tiempo requerido para hacerlo resta sus opciones para realizar otras actividades, como incorporarse al mercado laboral o dedicarse a actividades recreativas o de descanso (Aguirre, García

9 Estas cifras no se aprecian en la tabla l pero son una desagregación del rubro número 4, Cuidados no remunerados a miembros del hogar. 
y Carrasco 2005, 1), menguando así su desarrollo profesional, calidad de vida y bienestar (Damián 2014).

Considerando que es la mujer la encargada de las labores domésticas y de cuidado de integrantes del hogar, su cada vez mayor participación en el mercado laboral, el envejecimiento que se avecina a mediano plazo y la incapacidad de los servicios de asistencia social y de salud para hacerse cargo del creciente número de personas demandantes de sus prestaciones (Huenchuán y Guzmán 2008), cabe preguntarse cuál debería ser el modelo de distribución de actividades -tanto en participación como en tiempo- entre hombres y mujeres necesario para lograr el equilibrio de actividades diarias y la equidad entre géneros.

García y Oliveira (2007) reportan que es común encontrar que la participación de los varones es mayoritariamente en tareas que requieren menos horas de trabajo diario y que generalmente son identificadas como masculinas. Estas inequidades en la cantidad de horas dedicadas al trabajo doméstico también impactan en la calidad de vida de las mujeres. Rojas reporta que "en el caso de las mujeres asalariadas la estrategia es el alargamiento de su jornada cotidiana en detrimento de sus horas de descanso, de sueño y de esparcimiento. Aun los sábados y los domingos son días de trabajo que se dedican a la 'limpieza profunda' en la casa” $(2010,44)$.

Si pensáramos en un modelo ideal de distribución de actividades diarias en el hogar, se vuelve imprescindible plantear la necesidad, por un lado, de disminuir la cantidad de horas que los hombres destinan al trabajo remunerado y, por el otro, de un mayor equilibrio en la participación de los hombres y las mujeres en labores domésticas, sobre todo en los casos donde las mujeres se encuentran incorporadas al mercado laboral, ya que en muchos casos además del trabajo fuera de casa también son ellas las únicas encargadas de estas tareas.

Otro planteamiento que surge de estos resultados es que se requieren políticas de apoyo, destinadas principalmente a las mujeres, que les den acceso a guarderías dignas que les permitan no tener que dedicar tanto tiempo al cuidado de miembros del hogar e incorporarse al mercado laboral con la tranquilidad de que sus seres queridos están bien atendidos. Aunque también son necesarias políticas de permisos a los padres para el cuidado de los hijos como licencias de paternidad, ya que en las legislaciones actuales apenas se discute su conveniencia.

La literatura más reciente sobre los regímenes de bienestar destaca el papel de los hogares y las familias, junto al mercado y al Estado, como espacios proveedores de bienestar colectivo a través del aporte del trabajo no remunerado de sus miembros, fundamentalmente de las mujeres. Ello supone ampliar la noción de trabajo para integrar todas aquellas actividades humanas que generalmente quedan invisibilizadas a las estadísticas y a las cuales, por lo tanto, no se les asigna valor alguno. Las actividades dirigidas a producir bienes y servicios para el mercado han sido priorizadas y destacadas tanto en los cálculos como en los análisis e interpretaciones, dejando de lado aquellas tareas dirigidas al bienestar y al sostenimiento de la vida cotidiana. Al arrojar luz sobre estas actividades se evidencia la existencia de relaciones sociales inequitativas en el reparto del trabajo no remunerado tanto en los hogares como en la distribución social del trabajo remunerado y no remunerado. Ello provoca problemas en la vida cotidiana que erosionan las posibilidades de las mujeres de lograr autonomía económica y bienestar personal, y explican las 
diferencias de oportunidades que ellas tienen para participar en la vida social y política (INE 2008). En este sentido, la literatura avala estos resultados al constatar que:

La tendencia en el uso del tiempo de las parejas muestra que, en los países occidentales, mientras que el trabajo remunerado llevado a cabo por las mujeres se ha doblado desde los años sesenta, su dedicación a trabajo no remunerado ha disminuido considerablemente. Ahora bien, el incremento en trabajo remunerado no se ha visto compensado por un descenso equivalente en trabajo no remunerado, por lo que ha sido denominado como revolución cuya principal consecuencia es la concatenación de la jornada laboral con las tareas domésticas por parte de las mujeres, el denominado segundo turno (Ajenjo y García 2004, 3).

Ahora bien, con el fin de conocer a los jefes de hogar y cónyuges que analizaremos y dar buena cuenta de su participación y distribución del tiempo en las distintas actividades diarias, primero los identificaremos. Para ello elaboramos una descripción de sus principales características sociodemográficas, entre las que están: edad, situación conyugal, nivel escolar y ocupación (gráficas 1, 2, 3 y 4). Trabajamos con estas variables porque consideramos que son las que mejor dan cuenta de las características que hacen la diferencia en la distribución del tiempo de las personas.

El grupo de población analizada -jefes y cónyuges que desempeñan actividades remuneradas- muestra que la mayoría se ubica entre los 30 y 59 años de edad, variable que se encuentra relacionada con las edades productivas. Y como es de esperarse existen más hombres que mujeres en estas actividades (gráfica l).

Las proporciones de personas menores de 30 años y de 60 años y más son menores, aunque no son despreciables, lo que evidencia que a edades jóvenes y avanzadas la participación económica es importante en nuestro país.

Gráfica 1. Distribución porcentual de los jefes y cónyuges de 12 años y más por

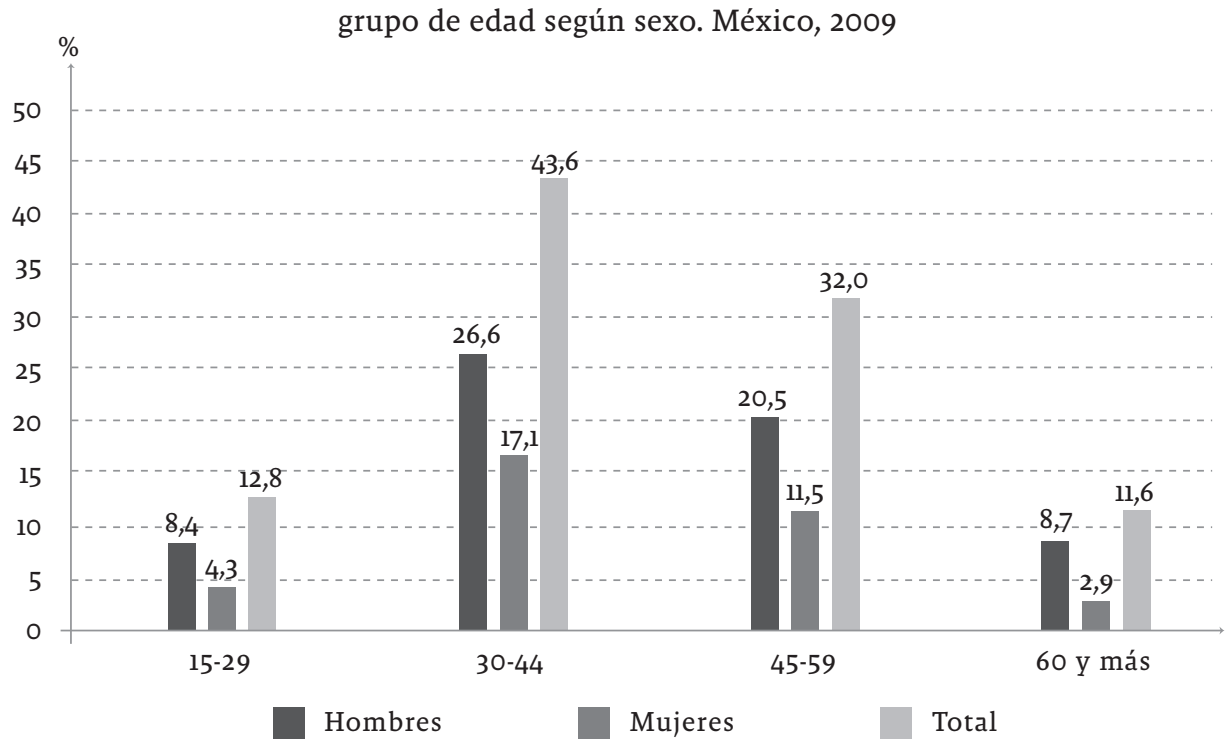

Fuente: elaboración propia con datos de la ENUT-09 (Inegi 2010). 
En la gráfica 2 podemos observar los datos según la situación conyugal de los jefes y cónyuges de 12 años y más que trabajan en actividades remuneradas. En esta se aprecia claramente que la mayoría son individuos que se encuentran unidos o casados, tanto en hombres como en mujeres. Las proporciones que se ubican como algunas vez unidos(as) y como solteros(as) son mayores en el caso de las mujeres que de los hombres. Aspectos relacionados con la menor reincidencia de las mujeres al matrimonio, una vez que hubo una ruptura de unión, a su mayor sobrevivencia, y al desbalance de los mercados matrimoniales que provocan excedentes de mujeres solteras (Hernández 2003).

Gráfica 2. Distribución porcentual de los jefes y cónyuges de 12 años y más según situación conyugal y sexo. México, 2009

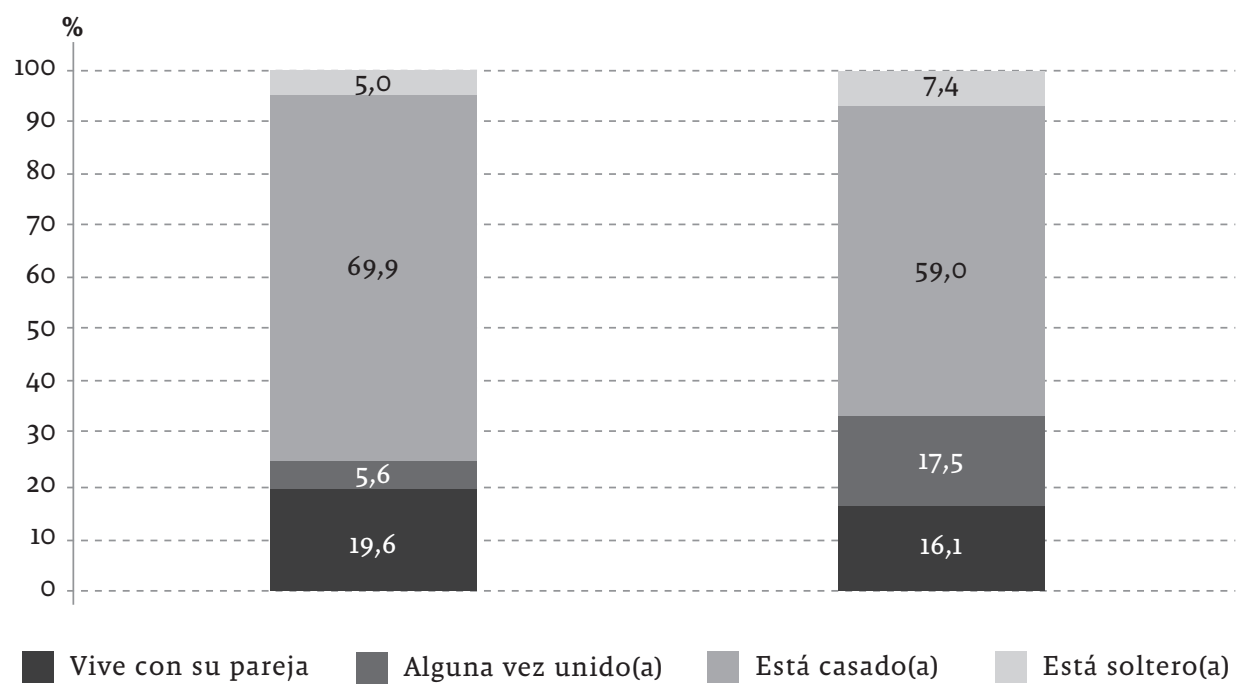

Fuente: elaboración propia con datos de la ENUT-09 (Inegi 2010).

Lo anterior pone en evidencia una cierta proporción de mujeres insertas en el mercado laboral porque así lo requieren: se encuentran solteras, separadas, divorciadas o viudas, sin contar con una pareja que comparta con ellas las responsabilidades de manutención. Este dato se confirma al obtener la desagregación por jefatura de hogar donde encontramos que $75 \%$ del total son jefes de hogar y $25 \%$ cónyuges. De los jefes de hogar, la mayoría, $62 \%$ son hombres y $13 \%$ son mujeres, una proporción importante. Mientras que los hombres cónyuges solo representan $2,4 \%$ del $25 \%$ total.

En cuanto al nivel escolar de este grupo de población (gráfica 3) encontramos que su distribución muestra un mayor número de hombres en casi todas las categorías; primaria, secundaria, preparatoria y equivalente, profesional y posgrado. La única excepción es la categoría sin escolaridad donde el número de mujeres supera al de los hombres (evidenciando el rezago que aún se presenta en materia educativa entre hombres y mujeres en México).

En la gráfica 4 presentamos la distribución porcentual de jefes y cónyuges que trabajan de manera remunerada de acuerdo con su posición en la ocupación. 
Gráfica 3. Distribución porcentual de los jefes y cónyuges de 12 años y más por nivel

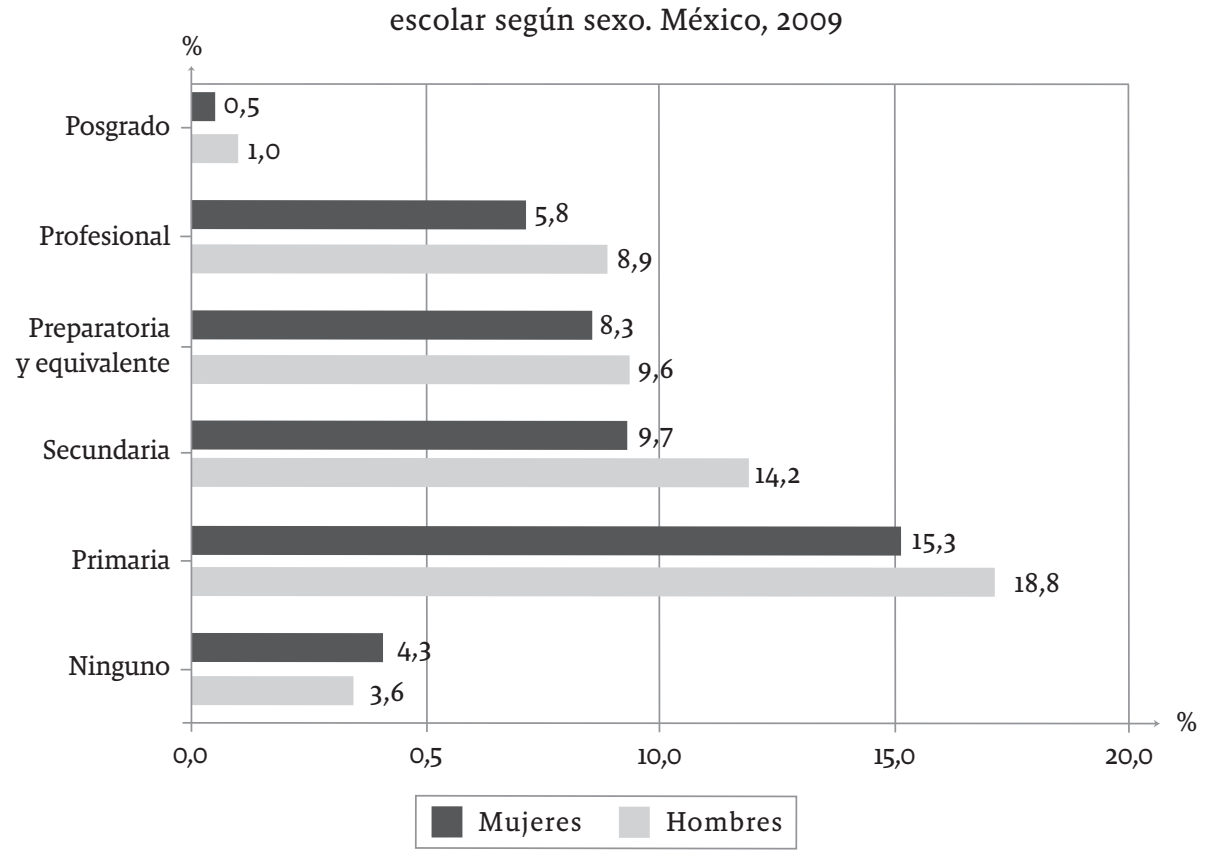

Fuente: elaboración propia con datos de la ENUT-09 (Inegi 2010).

Gráfica 4. Distribución porcentual de los jefes y cónyuges de 12 años y más por posición en la ocupación según sexo. México, 2009

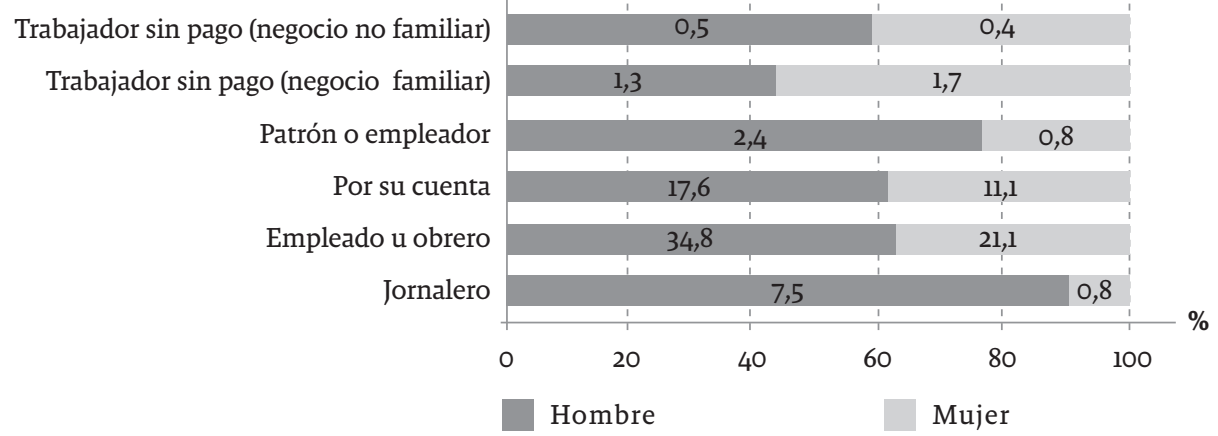

Fuente: elaboración propia con datos de la ENUT-09 (Inegi 2010).

Aquí observamos que las mayores proporciones de mujeres se encuentran en posiciones que muestran sus desventajas ante los hombres como es trabajador sin paga en negocios familiares; y existe una baja proporción de mujeres en categorías altas como patronas o empleadoras.

Habiendo dado un panorama del grupo de población en estudio, a continuación se presentan los resultados sobre su participación y tiempo en las distintas actividades cotidianas, desagregados por sexo (gráfica 5). 
Gráfica 5. Distribución porcentual del tiempo dedicado por la población de 12 años y más total y económicamente activa en actividades cotidianas según sexo. México, 2009 (horas promedio semanales)

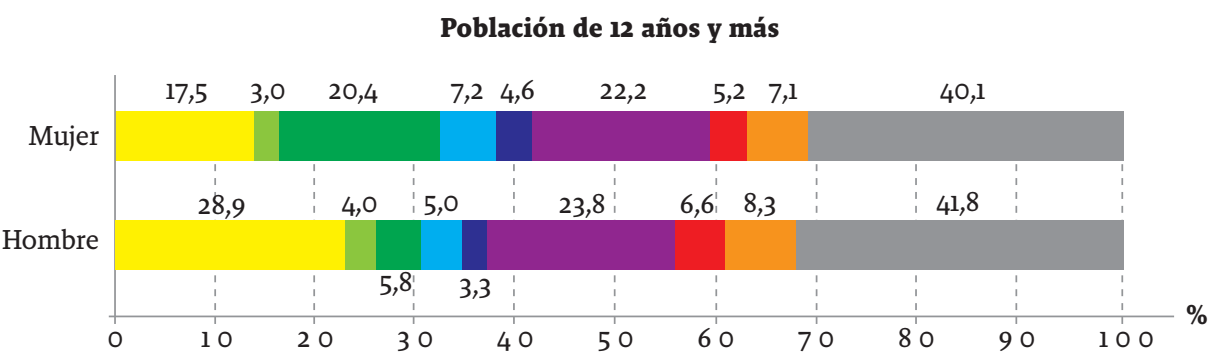

Jefes y cónyuges de 12 años y más económicamente activos

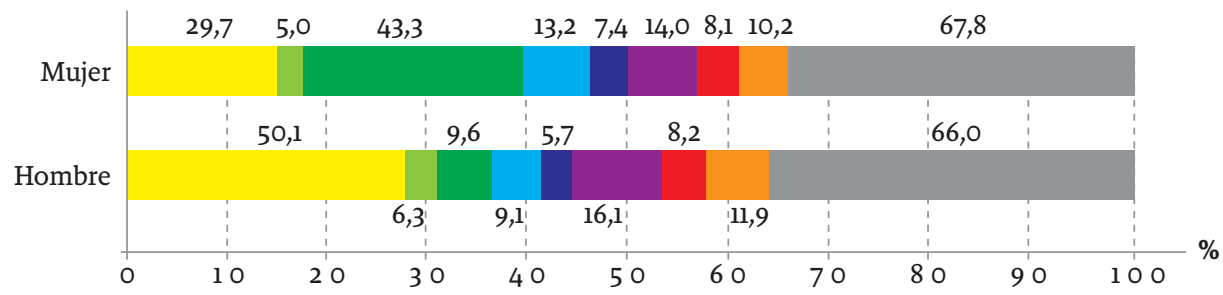

Trabajo remunerado (ocupación y empleo)

Actividades relacionadas con el trabajo remunerado

Actividades dom\{esticas no remuneradas para el propio hogar

Cuidados a miembros del hogar no remunerados

Actividades no remuneradas para otros hogares, la comunidad y trabajo voluntario

Aprendizaje y estudio

Convivencia y actividades recreativas

Utilización de medios masivos de comunicación

Cuidados personales

Fuente: elaboración propia (ver tabla 1 y anexo 1).

En esta gráfica plasmamos la distribución porcentual del tiempo promedio semanal que dedicaron hombres y mujeres a las diferentes actividades cotidianas, siendo el resultado de estas un $100 \%$. Lo anterior en virtud de que, aunque estamos conscientes de que hombres y mujeres no declaran el mismo número de horas a la semana ${ }^{10}$, una manera de aproximarnos a esta comparación es considerando cómo distribuyen la totalidad de su tiempo, para lo cual es pertinente utilizar porcentajes. Con el fin de no perder de vista los tiempos promedios semanales obtenidos en cada una de las actividades consideradas, colocamos también un rótulo en las series mostradas, referidas a las horas promedio se-

10 Situación que se relaciona con la subjetividad del concepto de tiempo que remite a aspectos cualitativos y concepciones del tiempo diferentes en cada grupo social, escenario histórico y contexto cultural (Nieves 2008). 
manales dedicadas a estas labores, las cuales no deben sumar 100 ya que no son porcentajes.

Los datos evidencian que, la población mayor de 12 años, presenta importantes diferenciales en las distribuciones de tiempo total. Lo primero que llama la atención es el tiempo dedicado al trabajo remunerado donde los hombres dedican casi el doble de tiempo con respecto a las mujeres (28,9 horas versus 17,5$)$, de acuerdo con roles de género tradicionales. En contraste, las mujeres dedican 20,4 horas semanales al trabajo doméstico no remunerado, mientras que los hombres dedican solo 5,8 horas semanales; casi tres veces más de tiempo, lo que evidencia nuevamente patrones persistentes en nuestra sociedad. Las demás actividades presentan cifras similares en cuanto a dedicación de tiempo.

Los datos aquí presentados sobre jefes y cónyuges muestran nuevamente que son los hombres los que participan prioritariamente en el mercado laboral y en actividades de autoconsumo (trabajo remunerado), así como en actividades relacionadas con el trabajo, como buscar trabajo y trasladarse al mismo, que representan alrededor de $30 \%$ de su tiempo semanal. Los jefes de hogar y cónyuges hombres dedican 50,1 horas a este trabajo remunerado mientras que las jefas y cónyuges mujeres solo 29,7 horas. Estas cifras hablan de la fuerte carga que continúan manteniendo los hombres para ser proveedores económicos de sus hogares, a pesar del hecho de la fuerte proporción de jefas y cónyuges mujeres que dedican un número importante de su tiempo a este tipo de trabajo. El peso de los roles tradicionales no deja de sentirse a pesar de los cambios tangibles, sistemáticos y crecientes en relación con la participación de la mujer en el mercado laboral.

El tiempo que los jefes y cónyuges hombres destinan a actividades de trabajo no remunerado -trabajo doméstico, de cuidado de miembros del hogar y a actividades de apoyo a otros hogares, comunitario y voluntario- ocupa alrededor de $15 \%$ de su tiempo semanal. Y finalmente las actividades personales que están conformadas por actividades de aprendizaje y estudio, convivencia, utilización de medios masivos de comunicación y actividades personales les llevan alrededor de $55 \%$ de su tiempo.

Por su parte, las mujeres dedican un poco más de $15 \%$ de su tiempo semanal al trabajo remunerado, alrededor de $35 \%$ a actividades de trabajo no remunerado -doméstico, de apoyo y cuidado de miembros del hogar y apoyo a otros hogares, comunitario y voluntario- y aproximadamente 50\% a actividades personales.

Estas distribuciones ponen en evidencia nuevamente los roles de género, donde los hombres tienen asignadas las funciones de proveedor económico del hogar y las mujeres las tareas de reproducción. Muestran también que las mujeres tienen mayor carga de trabajo, remunerada y no remunerada-casi $50 \%$ de su tiempo-, mientras que los hombres destinan alrededor de $5 \%$ menos a este mismo; por lo cual las mujeres tienen menor disponibilidad de tiempo para realizar actividades personales.

Sin embargo, al comparar la participación del total de la población de 12 años y más con la de jefes y cónyuges económicamente activos notamos diferencias importantes en el desempeño de las actividades cotidianas. Se observa mayor dedicación de tiempo en actividades remuneradas de los jefes y cónyuges, de casi el doble, con respecto a la población total de 12 años y más. Un dato que 
resalta es el tiempo dedicado a actividades domésticas por parte de los jefes y cónyuges quienes aumentan, con respecto a la población total, su desempeño de manera importante así como el tiempo de cuidado a miembros del hogar y de actividades de apoyo a otros hogares, comunitario y trabajo voluntario.

Es importante evidenciar que la participación de los hombres, cuando son jefes y cónyuges, en actividades domésticas es mayor que la de los mujeres $(54 \%$ versus $46 \%$, pero al observar las horas promedio semanales la tendencia se revierte drásticamente, pues se observa que aunque los hombres realicen en mayor medida las actividades, quienes dedican más tiempo son las mujeres ( 9,6 horas promedio semanales versus 43,3 ). De acuerdo con García, el tiempo dedicado por los hombres a las actividades no remuneradas "todavía es muy reducido" $(2007,30)$. En el caso de las actividades personales notamos que las mujeres tienen cifras de participación inferiores a las de los hombres, lo que avala las aseveraciones de Rojas (2010) sobre la utilización de este tiempo para poder cubrir la sobrecarga de trabajo por parte de las mujeres. Y el tiempo dedicado es muy similar entre ambos.

Se observa entre los jefes y cónyuges económicamente activos y la población mayor de 12 años total que los primeros dedican mucho menos tiempo a actividades de aprendizaje y estudio que la segunda. Aspecto seguramente relacionado con el hecho de que se encuentran insertos al trabajo remunerado.

Finalmente, llama la atención las diferencias que se observan en la dedicación de tiempo a actividades personales (descansar, meditar, consulta médica, aseo personal, comer y dormir). Contrario a lo que podríamos suponer, bajo la idea de que quienes trabajan tienen menos disponibilidad de tiempo, los jefes y cónyuges económicamente activos dedican más tiempo semanal -alrededor de 25 horas semanales- a este tipo de actividades, con respecto a la población mayor de 12 años total. ¿Indica esto que las personas económicamente activas tienen más tiempo para estas actividades, o que deciden racionalmente dedicarles más tiempo?

\section{Reflexiones finales}

Los resultados obtenidos dan cuenta de la permanencia y del rezago en el reparto de las funciones cotidianas entre hombres y mujeres. La desigual participación en las actividades desempeñadas por ambos pone en evidencia estas inequidades, aunque son más evidentes cuando el tiempo se incorpora al análisis.

En un primer momento, los datos parecen indicar que cuando hombres y mujeres se encuentran insertos en el mercado laboral existe una mayor igualdad en la participación en las actividades cotidianas, originalmente consideradas como femeninas. Sin embargo, al analizar los tiempos dedicados a estas se observa que las inequidades persisten. Haciendo evidente una sobrecarga para las mujeres, ya que si sumamos el tiempo dedicado a actividades remuneradas y no remuneradas vemos que su tiempo disponible para las demás actividades, llámense personales, se reduce. Así como sucede con algunos hombres (jefes y cónyuges económicamente activos) que también tienen una sobrecarga importante.

Esta menor participación y dedicación de tiempo en actividades personales como convivencia social, descanso y utilización de medios masivos de 
comunicación debe considerarse, pues puede tener efectos en el bienestar de las personas. Tomando en cuenta la aseveración de Araceli Damián, quien sostiene que "entre las principales consecuencias de la falta de tiempo están la insatisfacción o satisfacción deficitaria de las necesidades humanas y el escaso desarrollo de las capacidades y potencialidades de los seres humanos" (2014: 18), tenemos mujeres que no cuentan con el tiempo suficiente para poder desarrollarse profesional, social y personalmente.

La caracterización de los jefes y cónyuges analizados muestra que son personas en edad activa (entre los 30 y 59 años) y que son los hombres quienes presentan mayores proporciones de participación. En cuanto a su situación conyugal, la mayoría están casados, en mayor proporción los hombres que las mujeres, quienes también tienen proporciones importantes en la caracterización alguna vez unidas (divorciadas, separadas y viudas). La escolaridad muestra mayores niveles entre los hombres que entre las mujeres; y la posición en la ocupación muestra que las mujeres tienen empleos menos calificados que los hombres. Esta situación analizada en conjunto con la distribución del tiempo vuelve a confirmar las desigualdades a las que se enfrentan las mujeres al insertarse en el mercado laboral.

Los datos presentados y analizados corroboran que en México pervive el modelo tradicional de familia que se encuentra a su vez sustentado en una división de actividades dentro de la pareja, que implica que aun si ambos cónyuges tienen actividad laboral en el mercado de trabajo, es la mujer la responsable en mayor medida de las tareas domésticas, del ámbito privado o reproductivas. El crecimiento sistemático y sostenido de la participación laboral de la mujer ha debilitado - pero no desaparece- el patrón histórico de conformación de la unidad familiar mexicana. En la actualidad, el arquetipo de parejas con doble proveedor es cada vez más fuerte; sin embargo, los datos evidencian que la doble actividad dentro de la familia aún dista de ser una realidad.

Es importante considerar que aún queda camino por andar en lo que respecta a la equidad de género. Hacen falta políticas públicas que permitan la conciliación de trabajo y familia dirigidas a las mujeres, que busquen su incorporación en el mercado laboral sin tener que recurrir a una disminución de su propio tiempo para el autocuidado o el ocio o que tengan la posibilidad de acceder a empleos calificados o posiciones ocupacionales altas como patrones o empleadoras. Se deben establecer distribuciones de tiempo "ideales" que garanticen un equilibrio que permita el desarrollo profesional, familiar, y personal pleno de las personas.

En este análisis se debe reconocer que en el transcurso de las últimas décadas las características de las familias mexicanas experimentaron profundas transformaciones que están evidenciando cambios sin precedentes en su historia y apariencia; cambios irreversibles que obligan a valorar las consecuencias de sus impactos en una sociedad desigual, en creciente pobreza y sumamente heterogénea. Reconocer que la diversidad es una de las características distintivas de las unidades familiares del México del siglo XXI es admitir que las políticas públicas se enfrentan a por lo menos dos grandes retos: integrar esa diversidad y apoyar a las familias más vulnerables de la sociedad para hacer frente a los inexorables cambios que experimentan. 
Si bien es cierto que las transformaciones de las familias son temas siempre presentes en los discursos políticos (en los que reiteradamente se hace hincapié en la preocupación por la "desintegración" de la familia) como ya se ha manifestado, poco y nada de ese interés se ha visto reflejado en las agendas de las políticas públicas de los distintos gobiernos que ha tenido México. Del mismo modo, los cambios socio-demográficos de las familias también han estado ausentes del diseño de las políticas públicas (Cabella 2007). Así, teniendo en cuenta la necesidad de buscar un punto de encuentro entre los cambios de la familia y el diseño de políticas públicas destinadas a estas unidades, se pueden identificar al menos tres grandes desafíos a los que hacer frente (Sandoval y Román 2009):

* Es imprescindible promover políticas públicas que reconozcan que la realidad de las zonas rurales es particularmente más compleja y en muchas situaciones más difícil para los grupos familiares que la vida en las grandes urbes.

* Es forzoso lograr un equilibro en las relaciones intergeneracionales, que asegure el bienestar a todos los grupos de edad que integran los núcleos familiares, y de género.

* Las políticas públicas deben incorporar en sus programas la heterogeneidad de los grupos familiares más allá de los modelos ideológicos predominantes.

Por otra parte, es menester reconocer que el estudio del tiempo tiene un papel central como revelador y estructurador de las actividades de las personas y de las desigualdades sociales. La importancia de la consideración del tiempo tiene que ver con que es un recurso acotado y poco elástico a nivel individual. Las personas tienen restricciones materiales y culturales para la selección de actividades y para elegir el tiempo que les dedican; su utilización depende de su ubicación en la estructura social y económica, y del orden de género existente. Si bien la alta dedicación de las mujeres al trabajo no remunerado puede aparecer como una opción libre, sus decisiones están determinadas por normas culturales y prácticas sociales, así como de los recursos disponibles. Es una categoría clave en el estudio de las relaciones de género pues proporciona evidencias empíricas de situaciones poco visibles relativas a la desigual distribución de trabajos y actividades de mujeres y varones. El desarrollo internacional de las encuestas sobre el uso del tiempo es un instrumento relativamente nuevo e innovador que permite dar luz sobre estas cuestiones. La sistemática recolección de información sobre el trabajo remunerado y no remunerado, y el tiempo dedicado a ello, permite dar seguimiento a la evolución de la carga global de trabajo entre varones y mujeres; así como la situación de la división sexual del trabajo en los hogares y las familias. Esto se transforma en un importante insumo para la elaboración de políticas públicas que apunten a la equidad de género (INE 2008).

Este trabajo no está exento de presentar algunas limitaciones que se han mencionado en distintos momentos del documento y que, trascendiendo los objetivos ahora propuestos, puede superarse. Quizá la más importante tenga que ver con el tipo de fuente de información utilizada y con el corte transversal de los datos. Así, no podemos dejar de señalar que el funcionamiento de las familias se ve directamente afectado por las transformaciones del ciclo vital (que 
altera incuestionablemente el uso del tiempo doméstico y extradoméstico) que no pueden captarse con nuestras encuestas de medición del uso del tiempo. Para ello es necesario continuar el trabajo de investigación a partir de la construcción de escenarios descriptivos como el ahora propuesto, por el camino del análisis longitudinal, de valores y de preferencias individuales.

\section{Referencias bibliográficas}

Aguirre, Rosario, Cristina García y Cristina Carrasco. El tiempo, los tiempos, una vara de desigualdad. Santiago de Chile: Serie Mujer y Desarrollo Cepal-Unidad Mujer y Desarrollo, 2005.

Ajenjo, Marc y Joan García. «El tiempo productivo, reproductivo y de ocio en las parejas de doble ingreso". Revista de Sociología, Vol. 96, n 3, 2001: 856-1.007.

Ajenjo, Marc y Joan García. «Cambios en el uso del tiempo de las parejas. ¿Estamos en el camino hacia una mayor igualdad?». Revista Internacional de Sociología, Vol. 42, $\mathrm{n}^{\circ}$ 2, 2004: 453-476.

Bosch, Esperanza, Victoria Ferrer y Margarita Gili. «Aspectos diferenciales en el uso del tiempo entre mujeres que trabajan fuera del hogar y las amas de casa». Psicotherma, Vol. 8, $\mathrm{n}^{\circ}$ 3, 1996: 527-531.

Cabella, Wanda. El cambio familiar en Uruguay: una breve reseña de las tendencias recientes. Montevideo: Fondo de Población de las Naciones Unidas (UNFPA), Trilce, 2007.

Cacique, Irene. «Participación en el trabajo doméstico de hombres y mujeres en México». Papeles de Población, Vol. 14, nº 55 (enero-marzo 2008): 173-200.

Damián, Araceli. El tiempo, la dimensión olvidada en los estudios de pobreza y bienestar. México D.F.: Centro de Estudios Demográficos, Urbanos y Ambientales (CEDUA), El Colegio de México, 2014.

Del Barrio, Elena. "Uso del tiempo entre las personas mayores». Boletín sobre envejecimiento (Observatorio de personas mayores), $\mathrm{n}^{\circ}$ 27, 2007: 1-42.

Durán, María-Ángeles. «El trabajo no remunerado y las familias». Ponencia presentada en Consulta técnica sobre contabilización de la producción no remunerada de servicios de salud en el hogar, de la OPS. Washington, D.C., 4-5 de diciembre de 2003.

Durán, María-Ángeles. El valor del tiempo. ¿Cuántas horas te faltan al día? Madrid: Espasa Libros, 2007.

Eurostat. Harmonised European Time Use Surveys. 2008 Guidelines. Methodologies and Working Papers. Luxemburgo: Office for Official Publications of the European Communities, 2009.

Flaquer, Luis. Las políticas familiares en una perspectiva comparada. Colección de Estudios Sociales, $\mathrm{n}^{\circ}$ 3. Barcelona: Fundación La Caixa, 2000.

García, Brígida. "Cambios en la división del trabajo familiar en México». Papeles de Población, Vol. 13, n 53 (julio-septiembre 2007): $23-45$.

García, Brígida y Orlandina De Oliveira. «Trabajo extradoméstico y relaciones de género: una nueva mirada». En Género, familias y trabajo: rupturas y continuidades. Desafíos para la investigación política, de María Alicia Gutiérrez, 49-87. Buenos Aires: Consejo Latinoamericano de Ciencias Sociales (Clacso), 2007. 
García, Brígida y Edith Pacheco. «Esposas, hijos e hijas en el mercado de trabajo de la Ciudad de México en 1995". Estudios Demográficos y Urbanos (Centro de Estudios Demográficos y de Desarrollo Urbano), Vol. 15, $\mathrm{n}^{0}$ 1, 2000: 45-63.

García, Joan. El uso del tiempo en las parejas de doble ingreso. Bellaterra: Tesis del Doctorado en Demografía, Departamento de Geografía, Centro de Estudios Demográficos, Universidad Autónoma de Barcelona, 2012.

Gómez, María. «Directrices y referentes conceptuales para armonizar las encuestas sobre uso del tiempo en América Latina y el Caribe». Documento presentado en la Conferencia Estadística de las Américas de la Comisión Económica para América Latina y el Caribe. México D.F., CEA-Cepal, Unifem, Instituto Nacional de las Mujeres-México, División de Asuntos de Género-Cepal, Instituto Nacional de Estadística y Geografía (Inegi), junio de 2010.

Hernández, Luis. El descenso de la mortalidad en México y su impacto sobre las poblaciones casaderas. México, D.F.: Tesis para obtener el grado de doctor en Estudios de Población, Centro de Estudios Demográficos y de Desarrollo Urbano, El Colegio de México, 2003.

Huenchuán, Sandra y José Guzmán. «Seguridad económica y pobreza en la vejez: tensiones, expresiones y desafíos para el diseño de políticas». Ponencia presentada en Curso Internacional Redistribución del tiempo. Un indicador de igualdad. Santiago de Chile, CEPAL, 19 al 30 de mayo de 2008.

Instituto Nacional de Estadística, República Oriental del Uruguay (INE). Uso del tiempo y trabajo no remunerado en el Uruguay. Módulo de la Encuesta Continua de Hogares. Septiembre 2007. Montevideo: INE, 2008.

Instituto Nacional de Estadística y Geografía (Inegi). Encuesta Nacional sobre Uso del Tiempo 2002. Tabulados Básicos Definitivos. Aguascalientes: Inegi, 2005.

Instituto Nacional de Estadística y Geografía (Inegi). Censo de Población y Vivienda 2010. Aguascalientes: Inegi, 2010.

Instituto Nacional de Estadística y Geografía (Inegi). Encuesta Nacional sobre Uso del Tiempo 2009. Metodología y tabulados básicos. Aguascalientes: Inegi, 2012.

Instituto Nacional de Mujeres (Inmujeres). «El trabajo de cuidados ¿Responsabilidad compartida?». Boletín Dirección de Estadística (diciembre 2013): 1-24.

Kuznesof, Elisabeth. «Women, Work and the Family in Latin America: A Life Course Perspective on the Impact of Changes in Mode of Production on Women's Lives and Productive Roles». En The Peopling of the Americas, Vol. 2, 71-114. Veracruz: IUSSP, 1992.

Meil, Gerardo. «El reparto desigual del trabajo doméstico y sus efectos sobre la estabilidad de los proyectos conyugales». Revista Reis, Vol. 11, 2005: 163-179.

Milosavljevic, Vivian y Odette Tacla. Incorporando un módulo de uso del tiempo a las encuestas de hogares: restricciones y potencialidades. Serie Mujer y Desarrollo. Santiago de Chile: Cepal-Unidad Mujer y Desarrollo, 2007.

Nieves, María. «Tiempos y espacios de mujeres». En Género y Pobreza. Nuevas Dimensiones, de Irma Arriagada y Carmen Torres, 88-110. Santiago de Chile: Isis Internacional, 1998.

Nieves, María. «El tiempo sociohistórico. El tiempo subjetivo». Ponencia presentada en Curso Internacional "Redistribución del tiempo. Un indicador de 
igualdad". Santiago de Chile, Cepal, Organización Panamericana de la Salud, Unifem, 19 al 30 de mayo de 2008.

Norman, Eloísa. «Maternidad y vida laboral ¿dos opciones contrapuestas?». Ponencia presentada en el VIII Reunión Nacional de Investigación Demográfica en México. Repensando la agenda de política y acciones en el ámbito poblacional. Guadalajara, septiembre 6 al 9 de 2006.

Organización Internacional del Trabajo (OIT). Trabajo y familia hacia nuevas formas de conciliación con corresponsabilidad social. Santiago de Chile: Oficina Internacional del Trabajo y Programa de las Naciones Unidas para el Desarrollo, 2009.

Organización de las Naciones Unidas (ONU). Guía de elaboración de estadísticas sobre el uso del tiempo para medir el trabajo remunerado y no remunerado. Nueva York: División de Estadística, Departamento de Asuntos Económicos y Sociales, 2006.

Pedrero, Mercedes. El trabajo doméstico no remunerado en México. Una estimación de su valor económico a través de la Encuesta Nacional sobre Uso del Tiempo 2002. México D.F.: Inmujeres, 2005.

Rivero, Estela y Carla Pederzini. «Is the Mexican Youth an Agent of Change? An Analysis of Gender and the Heterogeneity of Mexican 15 to 29 Years Old». Ponencia presentada en Applied Demography Conference. San Antonio Texas: Institute for Demographic and Socioeconomic Research and the Department of Demography-The University of Texas, 8 alio de enero de 2014.

Rogero, Jesús. "Costes ligados a la dependencia». Trabajo Social y Salud, n 54 , 2006: 145-172.

Rojas, Olga. «Género, organización familiar y trabajo extradoméstico femenino asalariado y por cuenta propia». Revista Latinoamericana de Estudios de la Familia, Vol. 2, 2010: 31-50.

Sandoval, Eduardo y Patricia Román. «Desafíos de las políticas públicas de México ante los cambios en la dinámica familiar». En Estudios y propuestas para el medio rural, de Rosa Martínez Ruíz, 75-96. México D.F.: UAIM, CAID, UAEMex, Colegio de Postgraduados Campus Puebla, 2009.

Sosa, Viridiana. «Estimación del tiempo de trabajo total: una evidencia de los roles de género en México». Ponencia presentada en X Reunión Nacional de Investigación Demográfica en México. México D.F., Sociedad Mexicana de Demografía, 3 al 6 de noviembre de 2010.

\section{Bases de datos}

Instituto Nacional de Estadística y Geografía (Inegi). Encuesta Nacional sobre Uso del Tiempo, 2009. http://www3.inegi.org.mx/sistemas/microdatos/encuestas. aspx?c=12826\&s=est (último acceso: 26 de julio de 2010). Base liberada en 2010.

Sistema Nacional para el Desarrollo Integral de las Familias. Encuesta Nacional sobre la Dinámica de las Familias, 2005. http://bdsocial.inmujeres.gob.mx/bdsocial/index.php/endifam-29 (último acceso: 22 de marzo de 2014). 
Anexo 1. Participación y tiempo de jefes y cónyuges de 12 años y más, económicamente activos, actividades cotidianas según sexo. México, 2009

\begin{tabular}{|c|c|c|c|c|c|c|c|c|c|}
\hline & \multicolumn{9}{|c|}{ Participación } \\
\hline & Hombre & $\%$ & Mujer & $\%$ & Total & $\%$ & Hombre & Mujer & Total \\
\hline $\begin{array}{l}\text { Jefe de hogar y cónyuge de } 12 \\
\text { años y más económicamente } \\
\text { activo }\end{array}$ & 19.335 .456 & 56,2 & 15.086 .489 & 43,8 & 34.421 .945 & 100 & & & \\
\hline $\begin{array}{l}\text { Actividades de trabajo } \\
\text { remunerado }\end{array}$ & 19.335.456 & 56,2 & 15.086 .489 & 43,8 & 34421.945 & 100 & 55,9 & 32,7 & 45,8 \\
\hline $\begin{array}{l}\text { Trabajo remunerado (ocupación } \\
\text { y empleo) }\end{array}$ & 19.335 .456 & 56,2 & 15.086 .489 & 43,8 & 34421.945 & 100 & 50,1 & 29,7 & 41,2 \\
\hline $\begin{array}{l}\text { Actividades relacionadas con el } \\
\text { trabajo remunerado }\end{array}$ & 17.761 .746 & 65,5 & 9.353.383 & 34,5 & 27.115.129 & 100 & 6,3 & 5,0 & 5,8 \\
\hline Buscar trabajo & 91.197 & 74,3 & 31.500 & 25,7 & 122.697 & 100 & 16,5 & 8,8 & 14,5 \\
\hline Traslados de trabajo & 17.670 .549 & 65,5 & 9.321 .883 & 34,5 & 26.992.432 & 100 & 6,3 & 5,0 & 5,8 \\
\hline $\begin{array}{l}\text { Actividades de trabajo no } \\
\text { remunerado }\end{array}$ & 18.700 .920 & 55,4 & 15.025 .156 & 44,6 & 33.726 .076 & 100 & 16,6 & 55,3 & 33,8 \\
\hline $\begin{array}{l}\text { Actividades domésticas no } \\
\text { remuneradas para el propio hogar }\end{array}$ & 17.906 .076 & 54,4 & 15.001 .484 & 45,6 & 32.907 .560 & 100 & 9,6 & 43,3 & 25,0 \\
\hline Preparación y servicio de comida & 9.840 .014 & 40,2 & 14.654 .112 & 59,8 & 24.494 .126 & 100 & 4,5 & 18,5 & 12,9 \\
\hline Limpieza de la vivienda & 11.370 .977 & 44,4 & 14.214 .572 & 55,6 & 25.585 .549 & 100 & 4,0 & 16,6 & 11,0 \\
\hline $\begin{array}{l}\text { Limpieza, cuidado y confección } \\
\text { de ropa y calzado }\end{array}$ & 9.300 .018 & 39,7 & 14.136 .552 & 60,3 & 23.436 .570 & 100 & 1,6 & 6,2 & 4,4 \\
\hline $\begin{array}{l}\text { Mantenimiento, instalaciones y } \\
\text { reparaciones menores del hogar }\end{array}$ & 7.341 .716 & 82,2 & 1.586 .939 & 17,8 & 8.928 .655 & 100 & 2,9 & 2,1 & 2,8 \\
\hline Administración del hogar & 14.558 .511 & 54,7 & 12.071.173 & 45,3 & 26.629 .684 & 100 & 1,5 & 1,5 & 1,5 \\
\hline Compras para el hogar & 10.515 .288 & 46,9 & 11.915 .143 & 53,1 & 22.430 .431 & 100 & 2,4 & 2,8 & 2,6 \\
\hline $\begin{array}{l}\text { Cuidados a miembros del hogar } \\
\text { no remunerados }\end{array}$ & $1,24,0.288$ & 53,7 & 12.271 .590 & 46,3 & 26.511 .878 & 100 & 9,1 & 13,2 & $\mathbf{1 1 , 0}$ \\
\hline $\begin{array}{l}\text { Cuidado y apoyo a niños y niñas } \\
\text { menores de } 15 \text { años miembros del } \\
\text { hogar }\end{array}$ & 6.339 .489 & 48,0 & 6.855 .321 & 52,0 & 13.194 .810 & 100 & 5,6 & 11,4 & 8,6 \\
\hline $\begin{array}{l}\text { Cuidado y apoyo a miembros del } \\
\text { hogar de } 15 \text { a } 59 \text { años }\end{array}$ & 12.917.068 & 54,3 & 10.868 .364 & 45,7 & 23.786 .432 & 100 & 4,3 & 4,7 & 7,5 \\
\hline $\begin{array}{l}\text { Cuidado y apoyo a miembros del } \\
\text { hogar de } 60 \text { años y más }\end{array}$ & 58.887 & 47,1 & 66.073 & 52,9 & 124.960 & 100 & 4,9 & 2,6 & 3,7 \\
\hline $\begin{array}{l}\text { Act. NR para otros hogares, la } \\
\text { comunidad y trabajo voluntario }\end{array}$ & 1.613 .078 & 39,1 & 2.516 .522 & 60,9 & 4.129 .600 & 100 & 5,7 & 7,4 & 6,7 \\
\hline Apoyo a otros hogares & 1.046 .732 & 32,6 & 2.160 .083 & 67,4 & 3.206 .815 & 100 & 5,5 & 7,9 & 7,1 \\
\hline $\begin{array}{l}\text { Actividades comunitarias / } \\
\text { Trabajo voluntario no } \\
\text { remunerado }\end{array}$ & 659.408 & 57,4 & 489.783 & 42,6 & 1.149 .191 & 100 & 5,2 & 3,4 & 4,4 \\
\hline
\end{tabular}




\begin{tabular}{|c|c|c|c|c|c|c|c|c|c|}
\hline & \multicolumn{3}{|c|}{ Participación } & \multicolumn{6}{|c|}{ Tiempo (horas promedio semanales) } \\
\hline & Hombre & $\%$ & Mujer & $\%$ & Total & $\%$ & Hombre & Mujer & Total \\
\hline \multicolumn{10}{|l|}{ Actividades personales } \\
\hline Aprendizaje y estudio & 402.734 & 45,0 & 491.826 & 55,0 & 894560 & 100 & 16,1 & 14,0 & 14,9 \\
\hline Aprendizaje y estudio & 402.734 & 45,0 & 491.826 & 55,0 & 894560 & 100 & 13,7 & 12,0 & 12,8 \\
\hline $\begin{array}{l}\text { Traslados para aprendizaje y } \\
\text { estudio }\end{array}$ & 322.531 & 44,5 & 402.517 & 55,5 & 725.048 & 100 & 2,9 & 2,4 & 2,6 \\
\hline $\begin{array}{l}\text { Convivencia y actividades } \\
\text { recreativas }\end{array}$ & 14.267 .836 & 55,4 & 11.486 .880 & 44,6 & 25.754716 & 100 & 8,2 & 8,1 & 8,1 \\
\hline $\begin{array}{l}\text { Convivencia social (familiar, } \\
\text { amigos u otros) }\end{array}$ & 12.587 .460 & 53,7 & 10.855 .610 & 46,3 & 23.443 .070 & 100 & 6,6 & 6,8 & 6,7 \\
\hline $\begin{array}{l}\text { Asistencia a eventos culturales, de } \\
\text { entretenimiento y/o deportivos }\end{array}$ & 1.870 .316 & 63,3 & 1.086 .157 & 36,7 & 2.956 .473 & 100 & 3,3 & 3,4 & 3,3 \\
\hline Aficiones y otros pasatiempos & 2.091 .932 & 61,0 & 1.336 .594 & 39,0 & 3.428 .526 & 100 & 3,9 & 3,8 & 3,9 \\
\hline Deporte y ejercicio físico & 4.969 .906 & 65,8 & 2.584 .735 & 34,2 & 7.554 .641 & 100 & 4,0 & 4,1 & 4,0 \\
\hline $\begin{array}{l}\text { Utilización de medios masivos de } \\
\text { comunicación }\end{array}$ & 16.884 .877 & 58,5 & 11.956 .315 & 41,5 & 28.841 .192 & 100 & 11,9 & 10,2 & $\mathbf{1 1 , 2}$ \\
\hline $\begin{array}{l}\text { Leer libros, revistas, periódicos u } \\
\text { otro por cualquier medio }\end{array}$ & 8.692 .113 & 59,8 & 5.855 .308 & 40,2 & 14.547 .421 & 100 & 3,2 & 2,8 & 3,0 \\
\hline Ver televisión & 14.799 .682 & 60,4 & 9.695 .470 & 39,6 & 24.495 .152 & 100 & 9,6 & 8,9 & 9,3 \\
\hline $\begin{array}{l}\text { Escuchar radio u otros medios de } \\
\text { audio exclusivamente }\end{array}$ & 3.438 .913 & 65,0 & 1.852 .948 & 35,0 & 5.291 .861 & 100 & 5,6 & 6,5 & 5,9 \\
\hline $\begin{array}{l}\text { Utilizar computadoras (video y/o } \\
\text { audio, internet, descarga de } \\
\text { archivos) }\end{array}$ & 2.343 .396 & 61,1 & 1.492 .081 & 38,9 & 3.834 .477 & 100 & 5,5 & 4,8 & 5,3 \\
\hline Cuidados personales & 19.319 .383 & 56,2 & 15.085 .892 & 43,8 & 34405.275 & 100 & 66,0 & 67,8 & 66,8 \\
\hline $\begin{array}{l}\text { Cuidados personales (cuidados de } \\
\text { salud, descansar y otros) }\end{array}$ & 7.064 .775 & 50,5 & 6.932 .697 & 49,5 & 13.997 .472 & 100 & 5,0 & 3,8 & 4,4 \\
\hline $\begin{array}{l}\text { Actividades fisiológicas (comer, } \\
\text { dormir) }\end{array}$ & 19.329 .598 & 100,0 & 15.026 .489 & 100,0 & 34.416 .087 & 100 & 59,2 & 60,1 & 59,6 \\
\hline $\begin{array}{l}\text { *Se excluyó de la clasificación co } \\
\text { el propio hogar, el cuidado de p } \\
\text { la ENUT-09. }\end{array}$ & ntas y & iente & las act ya qu & idades & preguntó & $\begin{array}{l}\text { no } \\
\text { or est }\end{array}$ & as ac & $\begin{array}{l}\text { adas } \\
\text { dade }\end{array}$ & $\begin{array}{l}\text { ara } \\
\text { en }\end{array}$ \\
\hline
\end{tabular}

Fuente: elaboración propia con datos de la ENUT-o9 (Inegi 2010). 